\title{
The Sustainable Project Management Utilization in French Wineries While Adapting to Climate Change
}

\author{
By Ruixin Zhang $^{1}$, Joel Carboni ${ }^{2}$
}

\begin{abstract}
Nowadays, the issue of climate change has attracted attention in various fields. The rise of global temperature makes humanity must take note of environmental protection and the Sustainability of different domains. The planting of vineyards and the production of wine have also been greatly affected. Since the Sustainable Development Goals (SDGs) officially became the 17 development goals set by the United Nations in 2015, sustainable project management development is at the forefront globally. In recent years, the wine industry has developed rapidly worldwide. However, global climate change is a challenge for French wineries if they want to maintain their high-quality wine style. Therefore, in order to cope with the impact of climate change on wine, wineries have begun to implement sustainable development project management in all aspects. Especially French wineries that make much account of Sustainability in this respect. This paper proposes the one aspect - Wine Production of CWW Conceptual model that can be used in the French wineries, Four Drivers of Sustainable Project Management Implementation Model to interpret the main drivers that impact project management implementation in the wine industry. Using mixed-method research approach, qualitative research with interview-based analysis is the primary method, as well as surveys used to interpret the elements of sustainable project management necessarily utilizing in French wineries that would help them to achieve green growth.
\end{abstract}

Keywords: Climate changes, Sustainable project management, French wineries, Green growth, Project management, Sustainability

\section{Introduction}

With the rapid development of society, the environment is confronted with a severe situation that has never been seen before. "global warming" is a frequent phenomenon in these years (IPPC, 2013a, 2013). The issue of climate change has an effect on the various field at present, which is a major problem and challenge for humanity, as it can drastically alter the current climate scenario, affecting mainly agriculture (Lorençone, Kamila Cunha de Meneses\&Jose Reinaldo da Silva Cabral de Moraes, 2010).

The wine industry is now developing rapidly worldwide, global warming has a great impact on both vineyards and winemaking process, which makes the wine industry start to implement the subject of sustainability. What's more, on the basis of data from International Organization of Vine and Wine (OIV), the global wine market has experienced a high degree of change and uncertainty from 2000 to 2010, which affected by factors such as the current geopolitical change situation, climate change and the impact of the epidemic (OIV, October 2020.) 


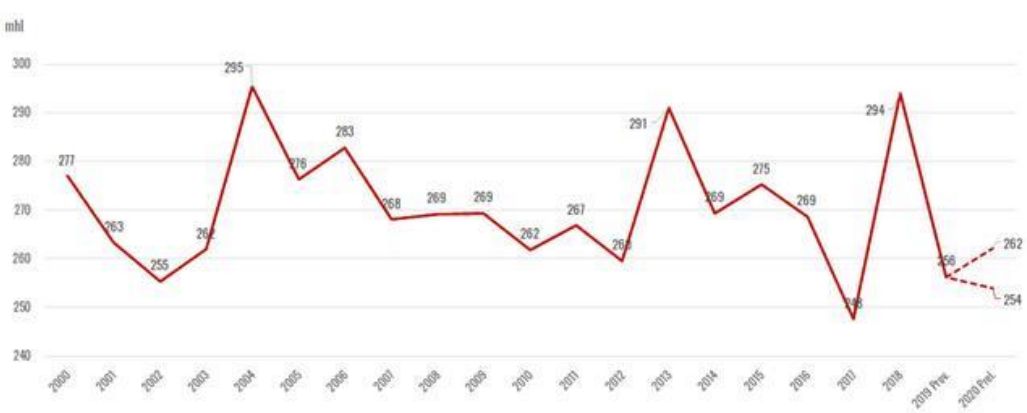

Fig. 1. 2000-2020 world wine production (excluding juice and grape mash)

In addition, the influence of climate variables becomes remarkable during the winemaking and the wine storage period (Wine'Tech, Aug 2013). Hence, there are plenty of wineries in the world that have taken steps to find out solutions to climate issues, sustainable and environmentally practices are becoming more effective (Michelle Renée Mozell, Liz Thach, 2014). Viticulture is very sensitive to the climate that usually called "terroir", the soul of the wine, which relates the sensory attributes of wine to the environmental conditions in which the grapes are grown (Gerard Seguin, Cornelis Van Leeuwen, 2007). The wine quality based on "terroir" directly affects consumers' satisfaction with the taste of wine (Mauracher C., Pocidano I., Sacchi G., 2016). Therefore, wineries will have to face the consequence of climate change on the viticulture, winemaking process, and storage. However, not just has impacts on viticulture and wine production, climate modification influences the wine business as well (Pierre Pradier, 2020).

With growing global wine consumption, the international wine trade trends to globalization apparently. ReportLinker gave us the analysis of the global wine market and market trends from 2020 to 2027, which pointed out that the Global Wine Market to Reach \$434.6 Billion by 2027 (ReportLinker, 2021).

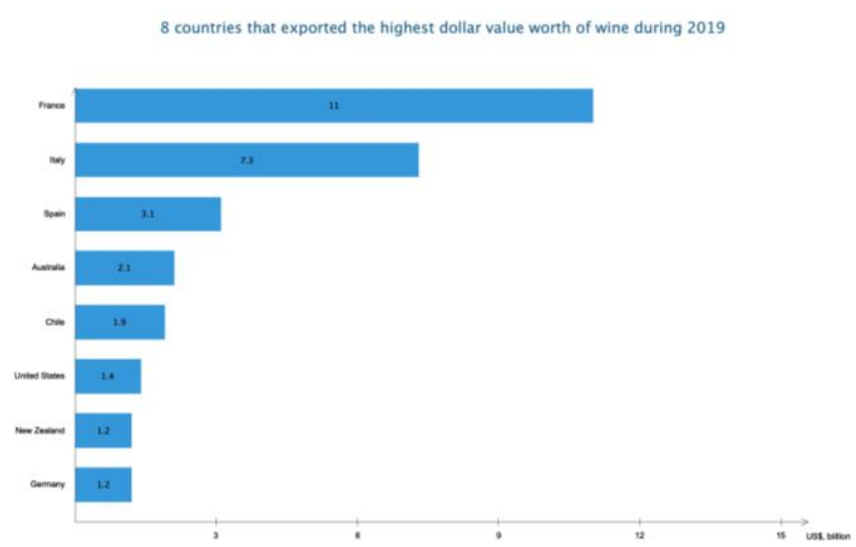

Fig. 2. Eight countries that exported the highest dollar value worth of wine during 2019

France as one of the most important wine export country plays a significant role in global wine business. The sales globally from wine exports by country amounted to US\$36.1 
billion in 2019, France is still in the leading position, accounting for $30.4 \%$ of total wine exports as Fig. 2 shows (Central Intelligence Agency, The World Factbook Field Listing: Exports - Commodities. 2020). We can obviously see the Fig.3 that present wine export from France have mostly doubled in less than twenty years from 2000 to 2020 (Eloise Trenda, Mar 2, 2021), although the amount has declined in some special periods, for example, the financial crisis in 2008 caused a decrease in 2009, and due to the impact of the global epidemic Covid-19 in 2020, exports have plummeted.

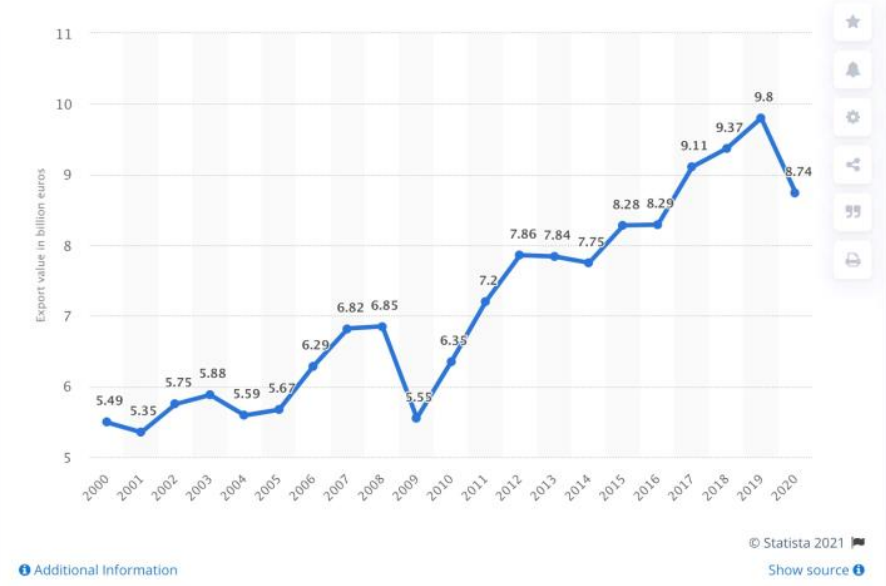

Fig.3. Wine export from France (2000-2021)

Therefore, Sustainability in the wine industry is receiving more and more attention from retailers, distributors, governments, environmental groups, and consumers as well (R.Dodds, S.Graci, S.Ko, L.Walker. 2013) Apparently, climate change has brought many impacts to the wine industry. There is a CWW model we designed for interpreting the relationship of consumer behaviors, wine production and wine companies which are the three main factors in wine marketing due to climate change. Since Sustainability is becoming the main force in the $21^{\text {st }}$ century, sustainable project management is playing a significant role in wine production. Therefore, Sustainability should be one of the goals pursued by wineries. We propose the Four Drivers of Sustainable Project Management Implementation Model that interprets the elements of the main four drivers that influence wineries practices. Project managers must know how to implement sustainable project management in an efficient way in the wineries, especially facing a dreadful environment. In recent years, more and more studies related to Sustainability have been carried out in different areas. People nowadays in the industry prefer to focus on high-performance projects, minimize waste, maximize value, and reduce cost (Eisenhardt, K. M., \& Graebner, M. E. 2007). Although the culture and personal technical knowledge make differences in perception and understand of Sustainability (Chekima B., Chekima S. Syed Khalid W., Igaua O. A., Sondoh S. L. 2016), sustainable project management is becoming very important which requires to pay more attention to economic, social, and environmental aspects. In terms of competence development, projects issues are not just system or information lag, but also related to organizational culture variables (Mauro L. 
Martens, Marly M. Carvalho. 2016).

In this paper, we aim to find out how the French wineries perspective for sustainable project management implemented for adapting to climate change and what kinds of achievement they have reached and will be practiced in the future. Building upon previous studies which discuss environmentally issues and sustainable viticulture practices implemented, we will use the one aspect of the CWW model we have offered before to present the sustainable project management the wineries should implement essentially. Furthermore, the barriers to improving further green growth and Drivers of Sustainable Project Management Implementation Model that we proposed elaborates the process of implementation will also be discussed as well.

\section{Related Work}

As one of the world's top and famous wine producing countries, the development of the wine industry in France is rising step by step, meanwhile, with the increasing trend of wine consumption globally, French wine is playing a more and more crucial role in the wine business international. "Terroir" is the French word used to describe all the ecological factors that make a particular type of wine special to the region of its origin (James E. Wilson, 1998). Especially after the millennium, France has paid more attention to the influence of terroir on wine cultivation and wine taste. However, one of the biggest influence factors on terroir is climate, which significantly impacts the planning and viticulture (John Gladstones. 2011). Therefore, climate change has always been a challenge for wineries. It affects aspects of terroir such as rainfall, water availability, soil quality and temperature, these elements are the key factors that reflect distinctiveness to geographical indications based on terroir (Lisa F. Clark, William A. Kerr. 2017). Consequently, French wineries should attend to concentrate on Sustainability.

However, climate change has always been the center of attention since the $21^{\text {st }}$ century. Climate change is a continuous spatiotemporal reality (Fotoula Droulia, Ioannis Charalampopoulos. 2021). Moreover, climate change has a strong impact on natural systems which can provide oxygen, clean water, food, storm and erosion protection, natural products, and potential future resources, thus providing speculations of climate variation is a challenge for human beings (Marcia McNutt. 2013). Global warming, carbon emissions greatly accelerated, have a much stronger effect on crops (Fábio M.DaMattaa, AdrianaGrandisb, Bruna C.Arenqueb, Marcos S.Buckeridgeb. 2010). It is no doubt that humanity has become aware that the environment is the one that offers both resources and prospects and the problem of environmental quality and protection has been worthy of attention (DN MOCUTA. 2017).

Consumer behavior changes along with climate variation, meanwhile, environment-related consumer behavior impacts international trade (Victoria K. Wells, Cerys A. Ponting \&Ken Peattie. 2010). Conversely, human behavior is integral not only to causing global climate change but also to responding and adapting to it (Susan Clayton, Patrick Devine-Wright, Paul C. Stern. 2015). As one of the biggest wine markets with great potential globally, the mid to high-income class population in China was about 112 million in 2019, and almost half of them were having imported wine at least twice a year (Ya-Ting Fan. 2019). China is one of the most attractive wine markets in the twenty-first century (Yuanbo Li and Isabel 
Bardají. 2017). Thus, the sustainability of the Chinese wine market is still very important for French wineries. Nowadays, many works focus on either sustainable consumer behaviors, or Chinese wine market analysis, there should be a gap thus we have to pay attention to Chinese wine consumer behaviors under the impacts of climate change which is significant for French wineries to know and become Sustainability as well.

As the social and environmental challenges that we are facing currently in our daily life, everywhere around the world, should be the evidence that Sustainability has been the most constant topic for all human beings, particularly in the project management area (Gilbert Silvius, Ron Schipper, Julia Planko. 2012). Nowadays, Project issues are not just system or information lag but also related to organizational culture variables (Mauro L. Martens, Marly M. Carvalho. 2017). A large number of French wineries have had several Sustainability programs that reduce the costs and maximize benefits, thus, kinds of environmental certification become popular (Jourjon, Frederique; Chou, Hsia-Chi. 2016). The winery is also continuously achieving sustainability in the following aspects : (1) water/waste/energy management; (2) risk management; (3) supply chain management; (4) employee training \& involvement; and (5) community relationships (R.Dodds, S.Graci, S.Ko, L.Walker. 2013). However, thought most of the French wineries have had a good job on green viticulture and energy management, there will be worth implementing sustainable project management in wineries to get more green growth.

\section{Methods}

\subsection{Wine Production in CWW Conceptual model}

We have offered the CWW Conceptual model (Fig.4.) before that identified the correlation between wine consumer behavior and climate changes successfully but have not interpreted Wine Production which is one of the important drivers in this model.

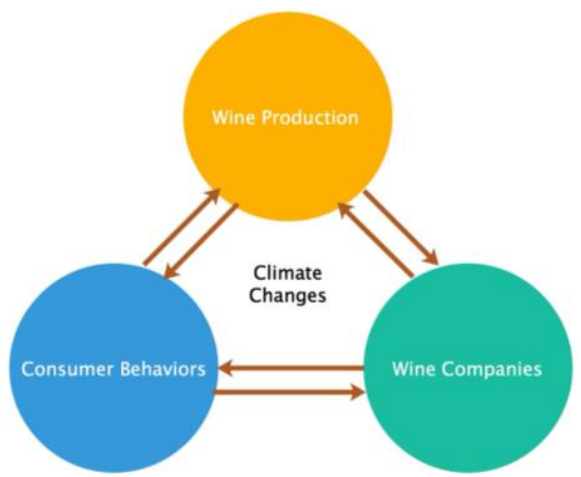

Fig.4. CWW Conceptual model in the wine industry

There is no doubt that the three main drivers in the triangle model which interact with each other intimately. Consumer behaviors will affect wine production and wine merchants these two elements will also influence consumer preferences or awareness conversely. Nowadays, with the growth of wine consumption worldwide and serious 
environmental issues, wineries have to pay more attention to environmental Sustainability practices future in this industry. Meanwhile, socio-ecological also shows the great influence on wine production style. Therefore, in order to implement sustainable project management in the wine production area, wineries need a better understanding of the market.

As an emerging wine market, China has huge potential and ranked the fifth top wine drinking countries, and one of the critical countries for French wine exporters as well (Fig.5.).
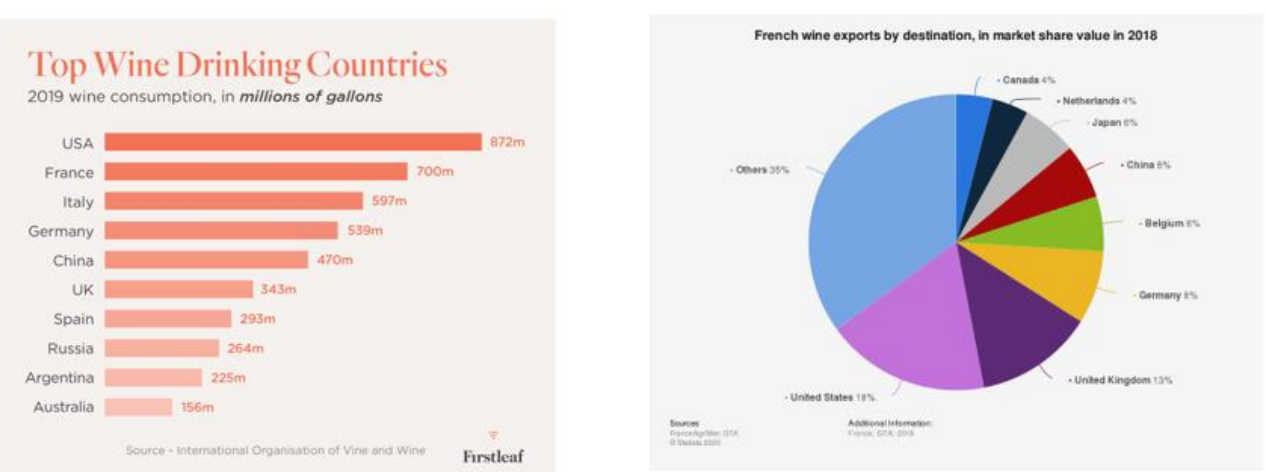

Fig.5. Top wine drinking countries in 2019 and French wine exports by destination in 2018

We have made online surveys that were distributed from January to May 2021. Participants from 20 provinces in China from North to South. In total, 101 surveys were collected to analyze out 1000 sent. However, the non-response rate may make some bias on data. The survey was placed on the major social platform, and people can freely choose whether they want to participate or not.

\section{Table 1:}

\begin{tabular}{|l|c|c|}
\hline \multicolumn{1}{|c|}{ Cronbach Reliability Analysis } & \\
\hline \multicolumn{1}{|c|}{ Item } & CITC & The deleted $\alpha$ \\
\hline \multicolumn{1}{|c|}{ Cronbach a } \\
\hline Do you think organic viticulture is necessary? & 0.396 & 0.596 \\
\hline Can you accept the difference in wine flavour due to climate change please? & 0.311 & 0.615 \\
\hline Do you know what Natural Wine is? & 0.466 & 0.576 \\
\hline Do you like to drink Natural Wine? & 0.303 & 0.623 \\
\hline Why you like Natural wine? & 0.355 & 0.611 \\
\hline Would you like to learn more about organic wine and natural wine? & 0.466 & 0.588 \\
\hline $\begin{array}{l}\text { Do you think it is necessary for the winery to carry out planting, brewing and } \\
\text { management that is conducive to environmental protection? }\end{array}$ & 0.378 & \multirow{2}{|c|}{0.593} \\
\hline \multicolumn{2}{|c|}{ Standardized Cronbach a: 0.690} & \\
\hline
\end{tabular}

We used SPSS to analyze the data's Reliability from survey in Table 1. Cronbach $\partial>0.6$, which concludes that there is a positive correlation between the analysis items, and the reliability level is credible. The 10-item questionnaire was structured but three of them have been deleted due to the weakness of the CITC value. Consequently, it comprehensively demonstrates that data reliability is of high quality and can be used for further analysis. 


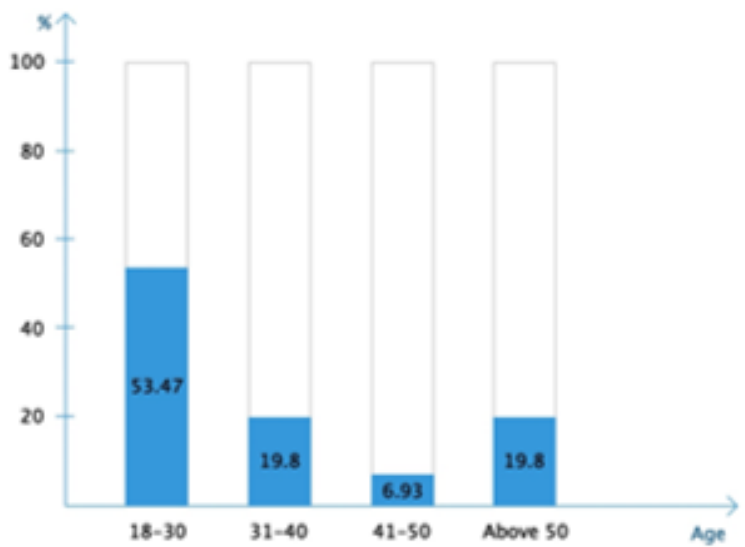

Fig.6. Age and Gender of participants

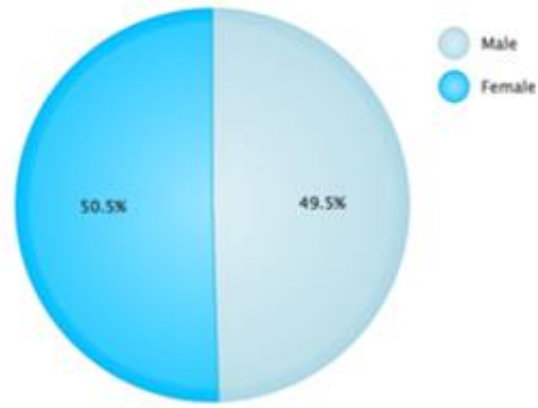

Fig.7.Proportion of employees

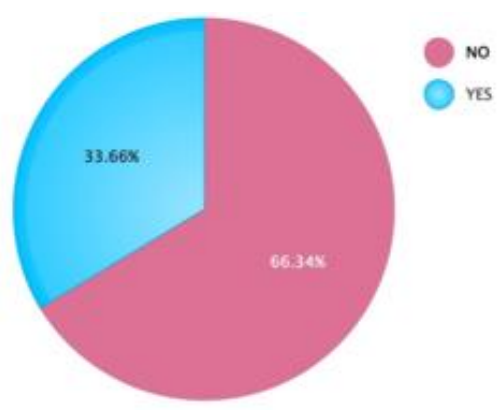

Proportion of employees in wine industry

Participants have a half male to female ratio, mainly young people from 18 to 30 years old as Fig.6. shows. It is not hard to conclude that Chinses young people are the driving force of the market. Afterwards, $66.34 \%$ of the participants are not working in the wine industry (Fig. 7.).

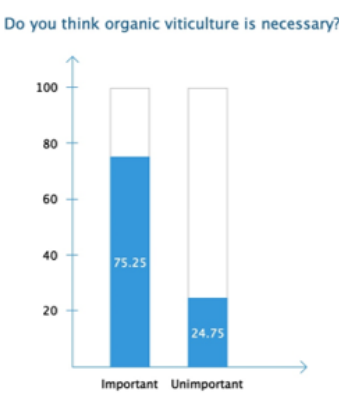

Fig.8.

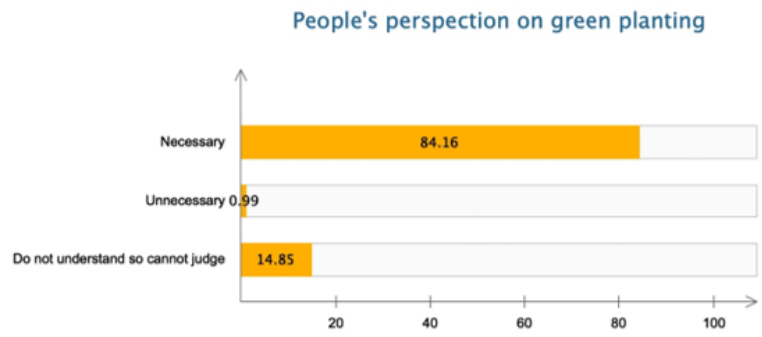


The Fig. 8 displays that the perception of the importance of organic wines with a positive attitude accounts for $75.25 \%$ among 101 samples. And above $80 \%$ of the participants support sustainable viticulture, just $0.99 \%$ of the amount provided negative thought on green planting.

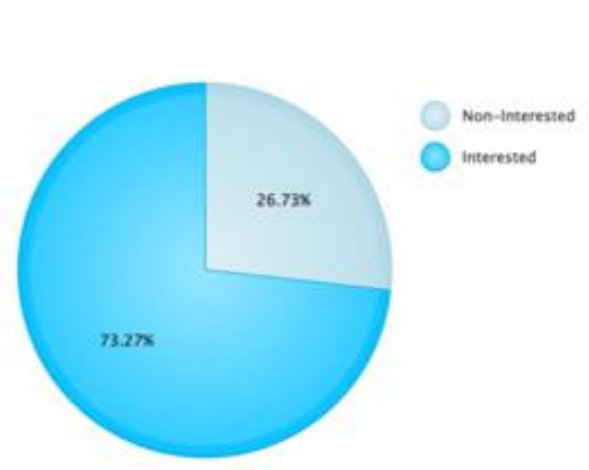

Fig.9. People's preference of learning more knowledge on organic wine and natural wine.

People who would like to know more about organic wine and natural wine occupied a great percentage of the total participant pools as Fig.9 shows, most of them can accept to replace the legal or commonly used grape varieties with other grape varieties you accept in order to better maintain or improve the taste of the wine due to climate change.

Table 2:

\begin{tabular}{|c|c|c|}
\hline \multicolumn{3}{|l|}{ Pearson Correlation Coefficient } \\
\hline & $\begin{array}{l}\text { Are you working in wine } \\
\text { industry }\end{array}$ & Are you the wine enthusiast \\
\hline Do you think organic viticulture is necessary? & 0.123 & -0.162 \\
\hline Would you like to learn more about organic wine and natural wine? & 0.204 & $-0.410^{* *}$ \\
\hline $\begin{array}{l}\text { Do you think it is necessary for the winery to carry out planting, brewing and management that is conducive } \\
\text { to environmental protection? }\end{array}$ & 0.22 & -0.143 \\
\hline Can you accept the difference in wine flavour due to climate change please? & 0.234 & -0.254 \\
\hline $\begin{array}{c}\text { Can you accept that in order to better maintain or improve the taste of wine due to climate change , we } \\
\text { replace the legal or commonly used grape varieties with other grape varieties? }\end{array}$ & -0.125 & -0.035 \\
\hline Do you know what Natural Wine is? & $0.602^{* *}$ & $-0.288^{*}$ \\
\hline
\end{tabular}

We analyze the Pearson of eight records by using SPSS as Table 2 unfolds. The relevance of people's occupations and wine and whether the participant is a wine enthusiast as the dependent variables, six questions on the left side of the form are independent variables. We can obviously observe that the correlation coefficient between the values is -0.410 , and it shows the correlation was significant at 0.01 level, which means negative correlation among whether the participant is a wine enthusiast and would you like to learn more about organic wine and natural wine. Are you a wine enthusiast? Do you know what Natural Wine is? The correlation coefficient between the values is -0.288 , and the significance is at the 0.05 level, which means that there is a significant negative correlation between them. Furthermore, the relevance of people's occupations and wine and do you know what Natural Wine is, the correlation coefficient between the values is 0.602 , and it shows a significant level of 0.01 , which means that there is a significant positive correlation between them. Apart from this, there is no correlation between other items. Therefore, based on 
the data analysis above, we can conclude that regardless of whether the profession is related to wine or whether is a wine enthusiast or not, it is considered necessary and very supportive for sustainable development in the wine industry although currently, only wine professionals know details about natural wine. Moreover, more stern situation needs to be faced due to environmental degradation. The implementation of sustainable development is imminent. Hence, it is imperative for the wineries to implement sustainable project management.

\subsection{Personal interviews}

We made in-depth interviews for 15 wineries\& wine association and 10 of them who showed appropriate representativeness. A convenience sampling approach was used. Although a growing number of wineries pay attention to Sustainability, the impact of climate change is still the main challenge for wineries that they should be always facing.

\begin{tabular}{|c|c|}
\hline $\begin{array}{l}\text { 1. Do you think climate change brings great impact on } \\
\text { wine? }\end{array}$ & 4. What are the achievements? \\
\hline $\begin{array}{l}\text { 2. What kinds of measures implemented in winery now } \\
\text { while adapting to climate change? }\end{array}$ & 5. What do you think can be improved in the future? \\
\hline 3. How do you think sustainable project management? & $\begin{array}{l}\text { 6. Do you think it is necessary to commit to } \\
\text { sustainable projet management? }\end{array}$ \\
\hline
\end{tabular}

Fig.10. Interview questions

I have taken 20-30 minutes for each people to communicate with the six questions above as Fig.10 shows. Ten representativeness who are working in either big wineries or government associations and come from different wine regions in France. Among the ten person, they all noticed that the great impacts of climate on terroir, on viticulture, on wine production. The temperature rising accelerates the ripening period of the grapes, which changes the flavor of the grapes. Interviewees from Champagne, Bordeaux, and Rhone Valley thought that some new grape varieties can be cultivated, or some niche grape varieties can be used to replace the original grape varieties for making an outstanding flavor, so as to resist the negative impact of global warming on the original grape varieties. This measure has been implemented in the Champagne area for many years. However, the method will be impractical in Burgundy areas although they admitted that it should be a good way. This is mainly due to the local culture and the strict hierarchy of wine production regions. So as the Bordeaux first-class wine.

When it comes to sustainable project management implementation, they all have the concept of Sustainability in mind. French wineries tried to put organic agriculture into effect 15 years before. France is one of the earliest countries with the concept of sustainable development. Reuse of wastewater can save water resources, optimize the supply chain, and organic viticulture. Above $90 \%$ of wineries have had groundwater management on slopes, made watering guide maps, improving harmony between soil and vines. All the participants said their wineries use the ecological infrastructure of the vineyard, such as the pruning and establishment of vines. What's more, wineries are advocated ecological renovation of tools and buildings, improvement of cleaning systems 
to reduce water consumption and reduce wastewater as much as possible. In recent years, many wineries have achieved $90 \%$ to $100 \%$ of the effective use of wastewater. Through 15 years of hard work, the carbon footprint has now been reduced by almost $20 \%$, and the use of chemical fertilizers has been reduced by $50 \%$.

Non-use or minimize the use of pesticides is also a manifestation of healthier wine. The reduced use or non-use of sulfur dioxide is the tracking of "terroir" and the respect for environmental sustainability. This is also one of the reasons why natural wine has become popular in recent years, which will have a huger market in the future. It is an inevitable trend and choice for the wineries to take the path of sustainable development, and it will also save a lot of costs and maximize the benefits.

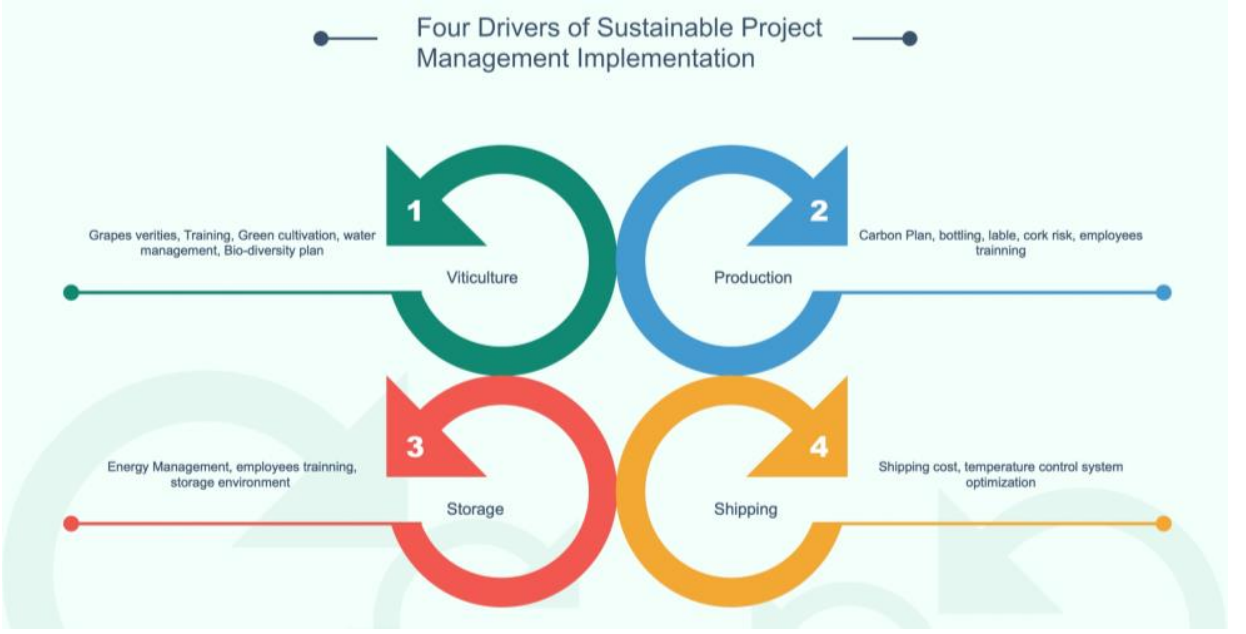

Fig.11. Four divers of sustainable project management implementation in wineries

Combining the views and ideas of the participants, we give four main drivers that influence the implementation of sustainable project management in the winery, which are viticulture, production, storage and shipping that are the things that the wineries need to pay attention to in the future (Fig.11). Although some achievements have been made in sustainable viticulture and production by mostly wineries, storage and shipping are the two main parts that wineries should think highly of in the future.

\section{Conclusions}

This paper states how essential the Sustainable project management concept should be deep-rooted in French wineries while adapting to climate change. CWW Conceptual model has been mentioned which shows the interaction between the three elements: wine production, consumer behaviors, and wine companies located in China. We mainly focus on one of the elements, wine production in this paper. A mixed-method is used with surveys and interviews interprets: Perspective of the consumer in the Chinese wine market for wineries using sustainable project management; The benefits of utilizing sustainable project management in French wineries. Due to the great influence that climate 
change should have on human beings, French wineries are necessary to continue implementing sustainable project management mainly in four areas: viticulture, production, storage, and shipping. Except for the sustainable viticulture and production system they are using, human resources sustainability is become more significant, for example, employee training, working environment optimization.

The study can be available used in all wine growing countries that not only help wineries be more Sustainability but also necessary for business and environmental improvement that gets more green growth. The implementation of sustainable project management is the only path for the wineries to go.

\section{Limitations}

Although the studies elaborated on the inevitability of French wineries to implement sustainable project management, it has a number of limitations. First, the sample size of effective surveys is relatively small compared to China's population base, so it cannot fully reflect the current market situation. Second, unstructured interviews have the least number of questions that the situation is more towards to the normal conversation. Although there are great opportunities to present the questions very clearly, there is no formal structure to the interview process, and the absence of a standardized set of questions made the reliability of interviews is questionable, and the results may not reflect the opinions of all wineries in France. Finally, there should be some uncertain factors that will affect the implementation of sustainable project management in wineries, such as social and economic issues, government intervention we have to consider.

\section{Reference}

IPPC, 2013a. Warming of the Climate System is Unequivocal. Report on Climate Change 2013: The Physical Science Basis - Summary for Policymakers, Observed Changes in the Climate System.

Lucas Eduardo de Oliveira Aparecido, Pedro Antonio Lorençone, João Antonio Lorençone, Kamila Cunha de Meneses\&Jose Reinaldo da Silva Cabral de Moraes (2010). Climate changes and their influences in water balance of Pantanal biome. Theoretical and Applied Climatology, 143, pages659-674 (2021).

International Organization of Vine and Wine (OIV), October 2020. https://www.oiv.int/en/oiv-life/2020world-wine-production-first-estimates

WineTech, Aug 2013. Vineyard Pest Management will be Challenged by Climate Change. winetech.com Available at: 〈http://www.winetech.co.nz/science/winemaking/item/215-vineyard-pestmanagement-will-be-challen ged-by-climate-change (accessed 28.11.13.).

Michelle Renée Mozell, Liz Thach, 2014. The impact of climate change on the global wine industry: Challenges \& solutions. Wine Economics and Policy 3 (2014) 81-89.

Gerard Seguin, Cornelis Van Leeuwen, 2007. The concept of terroir in viticulture. Journal of Wine Research, 23 Jan 2007.

Mauracher C., Pocidano I., Sacchi G., (2016) Wine tourism quality perception and customer satisfaction reliability: the Italian Prosecco District, Journal of Wine Research, Vol 27, number 4, 284-291.

Pierre Pradier, 2020. Chinese wine market industry-strategies and recommendations. New Horizons (https://nhglobalpartners.com/how-to-enter-the-wine-market-in-china-strategies-andrecommendations)

ReportLinker, 2021. Global industry analysis. https://www.reportlinker.com/p05010580/Global-WineIndustry.html?utm_source $=\mathrm{GNW}$ 
Central Intelligence Agency, The World Factbook Field Listing: Exports - Commodities. Accessed on April 29,2020

Eloise Trenda, Mar 2, 2021. https://www.statista.com/statistics/1150454/wine-export-value-from-france

R.Dodds, S.Graci, S.Ko, L.Walker, 2013, What drives environmental sustainability in the New Zealand wine industry? International Journal of Wine Business Research, issue 3, 134-168

Eisenhardt, K. M., \& Graebner, M. E. (2007). Theory building from cases: Opportunities and challenges. Academy of Management Journal, 50(1).

Chekima B., Chekima S. Syed Khalid W., Igaua O. A., Sondoh S. L. (2016). Sustainable consumption: The effects of knowledge, cultural values, environmental advertising, and demographics. International Journal of Sustainable Development and World Ecology. Vol 23, Issue 2, 2016.

Mauro L. Martens, Marly M. Carvalho, 2016. Key factors of sustainability in project management context: A survey exploring the project managers' perspective. International Journal of Project Management 35 (2017) 1084-1102.

James E. Wilson, 1998. Terroir: The Role of Geology, Climate and Culture in the Making of French Wines

John Gladstones, 2011. Wine, Terroir and Climate Change.

Lisa F. Clark, William A. Kerr, 2017. Climate change and terroir: The challenge of adapting geographical indications, first published: 07 July 2017

Fotoula Droulia, Ioannis Charalampopoulos. 2021. Future Climate Change Impacts on European Viticulture: A Review on Recent Scientific Advances, Atmosphere 2021, 12(4), 495

Marcia McNutt. 2013. Climate Change Impacts, Science 02 Aug 2013: Vol. 341, Issue 6145, pp. 435. DOI: $10.1126 /$ science. 1243256 .

Fábio M.DaMattaa, AdrianaGrandisb, Bruna C.Arenqueb, Marcos S.Buckeridgeb, 2010. Impacts of climate changes on crop physiology and food quality, Food Research International, Volume 43, Issue 7, August 2010, Pages 1814-1823

DN MOCUTA, 2017. Influence of the Climate Changes on the Human Life Quality,in Rural Areas, Revista de Chimie, 2017.

Victoria K. Wells, Cerys A. Ponting \&Ken Peattie. 2010. Behaviour and climate change: Consumer perceptions of responsibility. Journal of Marketing Management, volume 27, 2011 - Issue 7-8: Marketing in the 2010 British General Election - Perspectives, Prospect and Practice

Susan Clayton, Patrick Devine-Wright, Paul C. Stern, Lorraine Whitmarsh, Amanda Carrico, Linda Steg, Janet Swim \& Mirilia Bonnes, 2015. Psychological research and global climate change. Nature Climate Change volume 5, pages640-646 (2015)

Ya-Ting Fan.2019. "Chinese Wine Consumers Step Up." https://www.wineintelligence.com/chinese-wineconsumers-step-up/

Yuanbo Li and Isabel Bardají. 2017. A new wine superpower? An analysis of the Chinese wine industry. Cah. Agric. 2017, 26, 65002.

Gilbert Silvius, Ron Schipper, Julia Planko, 2012. Sustainability in project management. Published by Gower Puslishing Company, VT 05401-4405. USA

Mauro L. Martens, Marly M. Carvalho. "Key factors of Sustainability in project management context: A survey exploring the project managers' perspective. 'International Journal of Project Management 35 (2017) 1084-1102.

Jourjon, Frederique; Chou, Hsia-Chi; Gezart, Anna; E. Kadison, Amy; Martinat, Lea; Pomarici, Eugenio; Vecchio, Riccardo. 2016. Wineries Evaluation of Costs and Benefits of Sustainability Certification Program: The Case of Terra Vitis in France. Recent Patents on Food, Nutrition \& Agriculture, Volume 8, Number 2, 2016, pp. 138-147(10)

R.Dodds, S.Graci, S.Ko, L.Walker, 2013, What drives environmental sustainability in the New Zealand wine industry? International Journal of Wine Business Research, issue 3, 134-168) 